
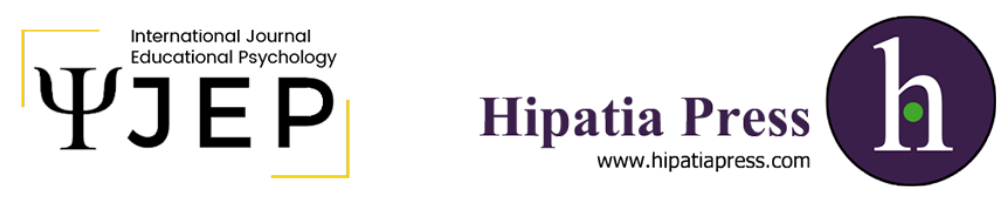

Instructions for authors, subscriptions and further details:

http://ijep.hipatiapress.com

\title{
Neurocognitive Evidence for Different Problem-Solving Processes between Engineering and Liberal Arts Students
}

Yu-Cheng Liu ${ }^{1}$, Chaoyun Liang ${ }^{1}$

1) National Taiwan University (Taipei, Taiwan)

Date of publication: June $24^{\text {th }}, 2020$

Edition period: June 2020 - October 2020

To cite this article: Liu, Y.-C., \& Liang, C. (2020). Neurocognitive Evidence for Different Problem-Solving Processes between Engineering and Liberal Arts Students. International Journal of Educational Psychology, 9(2), 104131. doi: $10.17583 /$ ijep. 2020.3940

To link this article:http://dx.doi.org/10.17583/ijep.2020.3940

PLEASE SCROLL DOWN FOR ARTICLE

The terms and conditions of use are related to the Open Journal System and to Creative Commons Attribution License(CC-BY). 


\section{Neurocognitive Evidence for Different Problem-Solving}

\section{Processes between Engineering and Liberal Arts Students}

Yu-Cheng Liu

National Taiwan University
Chaoyun Liang

National Taiwan University

\section{Abstract}

Differences exist between engineering and liberal arts students because of their educational backgrounds. Therefore, they solve problems differently. This study examined the brain activation of these two groups of students when they responded to 12 questions of verbal, numerical, or spatial intelligence. A total of 25 engineering and 25 liberal arts students in Taiwan participated in the experiment. The results were as follows. (i) During verbal intelligence tasks, differences between the two groups were observed in the information flows of verbal message comprehension and contextual familiarity detection in the problem-identifying phase, whereas no significant differences were found in the resolution-reaching phase. (ii) During numerical intelligence tasks, differences between the two groups were observed in the information flows of mental calculation and message comprehension in the problemidentifying phase and those of verbal perception and analogical reasoning in the resolution-reaching phase. (iii) During spatial intelligence tasks, differences between the two groups were observed in the information flows of spatial relation integration and spatial context memory retrieval in the problem-identifying phase and those of spatial attention and contextual relation integration in the resolution-reaching phase.

Keywords: electroencephalography, engineering students, liberal-arts students, problemsolving processes 


\section{Evidencias Neurocognitivas para Diferentes Procesos de Resolución de Problemas entre Estudiantes de Ingeniería y de Artes Liberales}

Yu-Cheng Liu

National Taiwan University
Chaoyun Liang

National Taiwan University

\section{Resumen}

Existen diferencias entre los estudiantes de ingeniería y de artes liberales debido a sus trasfondos educativos. Por lo tanto, resuelven sus problemas de forma diferente. Este estudio examina la activación cerebral de estos dos grupos de estudiantes cuando respondieron a 12 preguntas de inteligencia verbal, numérica o espacial. Un total de 25 estudiantes de ingeniería y 25 estudiantes de artes liberales en Taiwán participaron en el experimento. Los resultados fueron los siguientes. (i) Durante las tareas de inteligencia verbal, se observaron diferencias entre los dos grupos en los flujos de información de la comprensión de mensajes verbales y en la detección de familiaridad contextual en la fase de identificación de problemas, mientras que no se encontraron diferencias significativas en la fase de resolución. (ii) Durante las tareas de inteligencia numérica, se observaron diferencias en los flujos de información de cálculo mental y comprensión del mensaje en la fase de identificación de problemas y en aquellos de percepción verbal y razonamiento analógico en la fase de resolución. (iii) Durante las tareas de inteligencia espacial, se observaron diferencias entre los dos grupos en los flujos de información de la integración de la relación espacial y de la recuperación de memoria en el contexto espacial en la fase de identificación de problemas y en aquellos de atención espacial y de integración de la relación contextual en la fase de resolución.

Palabras clave: electroencefalografía, estudiantes de ingeniería, estudiantes de artes liberales, procesos de resolución de problemas 


\section{Liu \& Liang - Different Problem-Solving Processes}

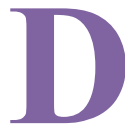

ifferences exist between students who majored in engineering and those who majored in liberal arts. Liberal arts students favour the general aspects of their work, whereas engineering students tend to focus on the specific aspects of their jobs (Neumann, 1983); this difference results from their educational backgrounds. Engineering education aims to introduce students to a wide range of technical subjects, form crossdisciplinary networks of engineering specialities, prepare students to effectively manage increasingly cross-disciplinary activities, and help students gain the ability to address the rapid changes to human lives caused by technological development. By contrast, liberal arts education enables students to acquire communication skills required for efficiently interacting with citizens from diverse societies and cultures, helps students to gain an appreciation and knowledge regarding the history of fine arts, and introduces students to the basic mathematics and science required to $\mathrm{m}$ manage financial affairs and everyday life (Jenkins, 2014). Therefore, liberal arts students address problems differently from engineering students (Bordoloi \& Winebrake, 2015).

Intelligence quotient (IQ) tests are generally designed to assess an individual's problem-solving ability, capture performance differences across cognitive tasks, and the results can be used to predict real-world outcomes (Gläscher et al., 2010). Cognitive neuroscientists have attempted to understand the organising principles that govern human intelligence, with new research providing novel insights into brain-based biomarkers, particularly the neural architecture of goal-directed, intelligent behaviour (Barbey et al., 2012; Miller \& Phelps, 2010). In the past 20 years, extensive functional neuroimaging evidence has indicated that the prefrontal cortex plays a central role in cognitive control and the flexibility of human intelligence (Bishop, Fossella, Croucher, \& Duncan, 2008; Duncan et al., 2000; Miller \& Cohen, 2001).

Neuroscientists still debate whether human intelligence reflects the combined performance of brain systems involved in IQ tasks or draws on specific systems mediating their interactions (Gläscher et al., 2010). The central question is whether prefrontal networks and distributed cortical regions are computationally necessary for the core features of human intelligence (Barbey et al., 2012; Deary, Penke, \& Johnson, 2010). According 
to an alternative framework, human intelligence depends on various cognitive processes that are mediated by functionally specialised brain regions, including the (i) temporal and occipital regions for processing sensory information, (ii) parietal regions for sensory integration and abstraction, (iii) frontal regions for reasoning and problem-solving, and (iv) anterior cingulate for response selection and automatic response inhibition (Barbey et al., 2012; Barbey \& Sloman, 2007; Gläscher et al., 2010). Accordingly, studies have indicated that education and cognitive activity was significantly correlated with both general cognitive ability and specific skills (Ritchie, Bates, \& Deary, 2015) and that the interaction of education and cognitive activity significantly affected episodic memory but not executive functioning (Lachman, Agrigoroaei, Murphy, \& Tun, 2010).

IQ tests contain three major question types. Each type examines different abilities, namely verbal, numerical, and spatial problem-solving (Carter \& Russell, 2008; Spearman, 1904), and demands different information processing, thus predicting different aspects of human performance (Oakhill, Yuill, \& Garnham, 2011). The language processing network, which comprises the medial frontal cortex, left temporal cortex, left dorsal and ventral frontal regions, and posterior cingulate, has long been considered crucial for the development of verbal intelligence (Basagni et al., 2017; Liu, Chang, Yang, $\&$ Liang, 2018). In addition, the frontoparietal network, which comprises the dorsolateral prefrontal cortex and intraparietal sulcus, is identified as the primary system for the development of numerical intelligence (Cohen Kadoshsend, Soskic, Iuculano, Kanai, \& Walsh, 2010; Kanjliaa, Lanea, Feigensona, \& Bedny, 2016). Finally, the spatial processing network, primarily comprising the right superior temporal and posterior parietal cortices, is considered crucial for the development of spatial intelligence (Ivanitskii et al., 2015; Liang et al., 2017; Yao, Lin, King, Liu, \& Liang, 2017).

Although cognitive neuroscience has progressed remarkably towards understanding human intelligence, relative contributions supporting highlevel cognition and predicting performance remain poorly characterised (Paul et al., 2016), particularly between different professional disciplines. Based on the aforementioned findings, the present neurocognitive study was conducted to characterise the brain activities exhibited by university students when they 


\section{Liu \& Liang - Different Problem-Solving Processes}

responded to various verbal, numerical, and spatial intelligence tasks. Particularly, electroencephalography (EEG) was used to assess the brain activities of students majoring in engineering and liberal arts. We recorded the EEG data of each participant in two phases of each experimental IQ task: the problem-identifying and resolution-reaching phases. This study investigated differences in the brain activations of engineering and liberal arts students when engaging in the problem-identifying and resolution-reaching phases of experimental tasks corresponding to verbal, numerical, and spatial intelligence. The outcomes can contribute to the design of interdisciplinary talent development programmes as well as identification of useful avenues of inquiry for future research.

\section{Methods}

\section{Participants}

A total of 25 engineering and 25 liberal arts students in Taiwan participated in the EEG experiment. The engineering students were majoring in either electrical or computer engineering, whereas the liberal arts students were majoring in either Chinese or foreign language. All the participants were Taiwanese second-year or third-year undergraduates who had normal or corrected-to-normal vision and no history of drug or alcohol abuse or cardiovascular or vestibular disorders. Because of signal malfunction or dropouts during the course of the study, the EEG data of only 19 engineering students ( 8 women and 11 men; aged 20-22 years) and 17 liberal arts students (10 women and 7 men; aged 20-23 years) were acquired for further analyses.

\section{Materials}

On the basis of the Taiwanese version of the Stanford-Binet Intelligence Scale, a comprehensive IQ test used globally to diagnose intellectual deficiencies in young people, we developed 12 items (four items each for verbal, numerical, and spatial intelligences). Verbal intelligence items comprised synonyms or antonyms, analogical relationships, word-building tests, and practical knowledge and understanding of social rules and concepts. 
An example of a verbal intelligence item is 'Which of the following is not like the others: (1) handsome, (2) flirtatious, (3) graceful, or (4) pretty?' Numerical intelligence items consisted of mathematical operations involving simple arithmetic (e.g. percentages, powers, and fractions), figures and thinking, and estimations and more global judgments. An example of a numerical intelligence item is: 'Which of the following is an illogical number followed by 111, 339, and 5525: (1) 8869, (2) 6645, (3) 9976, and (4) 7749?' Spatial intelligence included items that prompted mental generation and rotation of visual images, solving spatial navigation problems, and visualising objects from different angles (e.g. thinking about objects in three dimensions to draw conclusions from limited information). An example of a spatial intelligence item is 'Which cannot made by folding this labelled cardboard
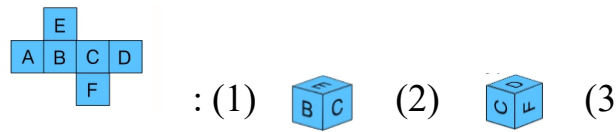

(3)

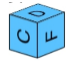

(4)

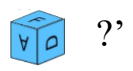

\section{Experimental Equipment and Procedure}

The participants received a detailed explanation of the experiment and were asked to sign consent forms after they arrived at the laboratory. Their brain responses were recorded using a 32-channel inflatable wireless K32S EEG headset with a sampling rate of $250 \mathrm{~Hz}$ and 16-bit quantisation. A single reference electrode was placed on the mastoid behind the ear, and electrode impedance was minimised $(\leq 5 \mathrm{~K} \Omega)$. This headset employed comb-like sensors that mitigated interference from hair and made unobstructed contact with the scalp for precise brain activity detection. The headset with springloaded dry electrodes and a soft cap maximised contact between all sensors and all parts of the scalp to ensure accuracy and quick placement. Scalp markers were placed in accordance with the international 10-20 system and aligned with underlying cerebral structures.

The experiment began after the participants had donned the headset and steady EEG signals were being received. The participants were asked to watch a prerecorded presentation on a computer screen and minimise their movements. We first recorded their brain responses for $30 \mathrm{~s}$ during resting 


\section{Liu \& Liang - Different Problem-Solving Processes}

periods to serve as a baseline, ensuring that an observed response was not present before the introduction of experimental tasks. The participants then worked mentally to determine which number belonged in the space with the question mark of each IQ test item. During the experiment, they were not permitted to use a pencil or paper or ask questions. We did not record the participants' answers, because the central focus of this research was problemsolving processes rather than correctness.

Short breaks were scheduled between items as intertrial intervals to prevent overlapping brain responses from being recorded. In other words, separate EEG data for problem-solving processes were acquired for each question. The experiment was completed in approximately 25 minutes, including experiment description and EEG headset testing. The process was identical for all the participants to ensure consistency in the experiment. On average, the engineering students spent approximately $10 \mathrm{~s}$ on each verbal question (mean $[M]=10.06 \mathrm{~s}$, standard deviation $[\mathrm{SD}]=3.08 \mathrm{~s}), 26 \mathrm{~s}$ on each numerical question $(M=26.22 \mathrm{~s}, \mathrm{SD}=5.62 \mathrm{~s})$, and $22 \mathrm{~s}$ on each spatial question $(M=$ $21.78 \mathrm{~s}, \mathrm{SD}=4.12 \mathrm{~s})$, whereas the liberal arts students spent approximately $10 \mathrm{~s}$ on each verbal question $(M=9.84 \mathrm{~s}, \mathrm{SD}=2.92 \mathrm{~s}), 28 \mathrm{~s}$ on each numerical question $(M=28.16 \mathrm{~s}, \mathrm{SD}=7.14 \mathrm{~s})$, and $25 \mathrm{~s}$ on one spatial question $(M=$ $24.90 \mathrm{~s}, \mathrm{SD}=6.32 \mathrm{~s})$.

\section{Data Analysis}

All collected data were carefully examined, and noise signals, including line noise, systematic noise, oculomotor activities, and muscle movements, were removed using a finite-infinite response filter with cut-off frequencies of 1 and $50 \mathrm{~Hz}$. Abnormal trends and extreme values of signals were detected using kurtosis with a five $z$-score threshold and removed manually. The removed channels were replaced with averages of the data of the corresponding (engineering or liberal arts) group. After removing noise and abnormal and extreme channels, filtered EEG signals were split into two phases; from the beginning of second 2 to the end of the second 3 (problem-identifying phase) and the final second (named as the resolution-reaching phase) (Hanson \& Bunzl, 2010). To generalise filtered EEG data, we averaged them respectively within the verbal, numerical, and spatial categories for each participant. The 
workflow is presented in Figure 1. All the aforementioned processes were performed using the EEGLAB toolbox (Delorme \& Makeig, 2004) either through native or plug-in routines.

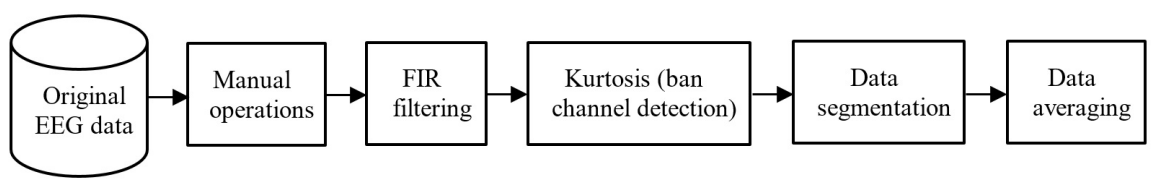

Figure 1. Work-flow of EEG data preparation

In this study, independent component analysis was performed with the infomax algorithm (Jung, Makeig, Mckeown, Bell, Lee, \& Sejnowski, 2001) to process filtered EEG data into separate quasi-independent signal sources. The pseudolocations of all quasi-independent signal sources, known as dipole locations, were estimated using DIPFIT (version 2.3) with the single equivalent current dipole model (Delorme, Palmer, Onton, Oostenveld, \& Makeig, 2012), a plug-in routine in EEGLAB. According to probe locations F3, F4, P3, and P4 of the 10-20 system, estimated diploes were divided among seven brain areas: the left frontal region (K1), right frontal region (K2), left temporal region (K3), frontoparietal region (K4), right temporal region (K5), left parieto-occipital region (K6), and right parieto-occipital region (K7) (Figure 2). Corresponding independent components (ICs) to partitioned dipoles were averaged by these areas. Averaged ICs were used to represent the signal for each brain area. The workflow of dipole partition is shown in Figure 3. 


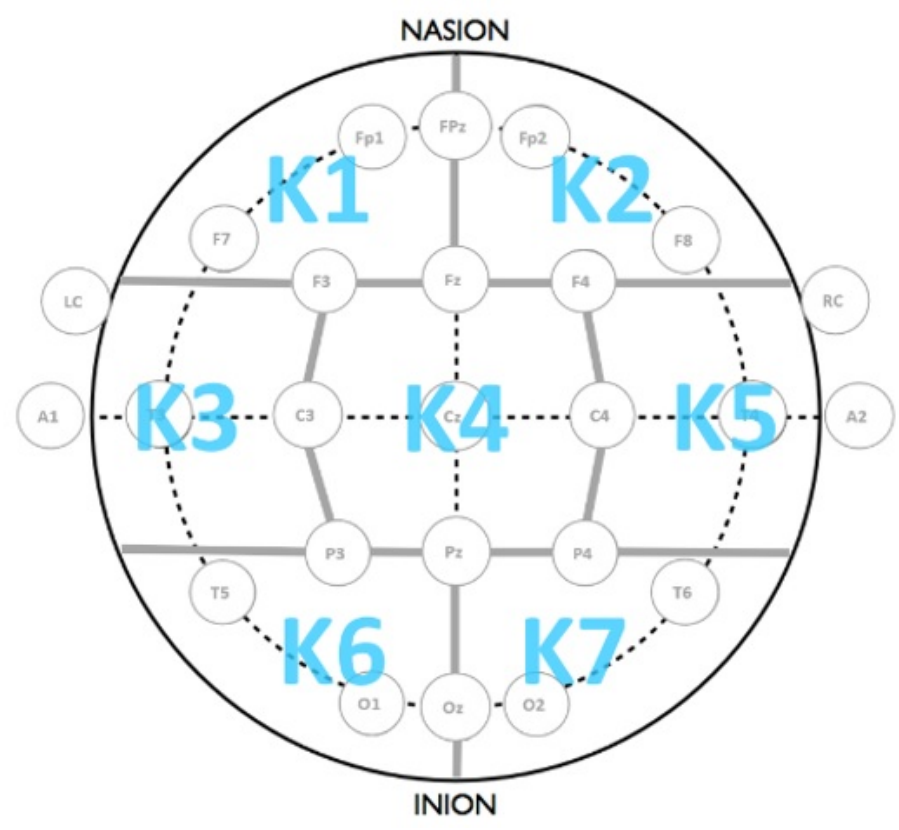

Figure 2. Montage of dipole partition

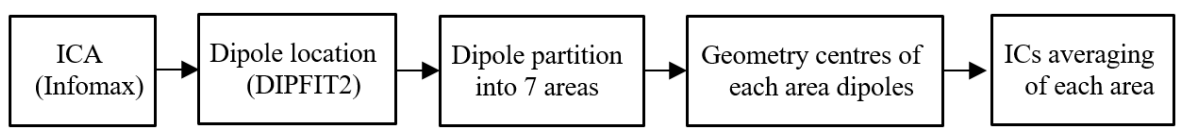

Figure 3. Work-flow of dipole partition processes

A multivariate vector autoregressive (MVAR) model has been widely used to analyse neural activity data and brain connectivity (Bressler \& Seth, 2011; Friston, Bastos, Oswal, van Wijk, Richter, \& Litvak, 2014; Lin et al., 2016) and is the commonest operational model of Granger causality (Granger, 1969). In this study, we adopted the multivariate Granger causality (MVGC) toolbox (Barnett \& Seth, 2014) to implement the MVAR model to investigate brain activity networks in a time domain. Compared with other tools (Delorme \& Makeig, 2004), MVGC improves computational efficiency and accuracy 
through asymptotical equivalent methods, namely ordinary least squares (OLS) and Durbin recursion, for maximal likelihood estimation. Additionally, MVGC improves statistical inference processes. Granger causality clarifies that if the past of a variable $x_{1}$ helps to predict the future of a variable $x_{2}$, then the general expression of the MVAR model and a $p$ th order MVAR are expressed as Equation 1. Let $\mathbf{X}$ consist of random variables $\left\{\mathbf{x}_{1}, \mathbf{x}_{2}, \ldots, \mathbf{x}_{\mathrm{T}}\right\} ; T$ is the total time points, $\mathbf{x}_{t}$ is an $n$-dimensional column vector with elements $x_{1 t}$, $x_{2 t}, \ldots, x_{\mathrm{n} t}$, and $t$ is an index of the time point. In this equation, $p$ is the model order that can be determined through order selection.

$$
\mathbf{x}_{t}=\sum_{k=1}^{p} \boldsymbol{A}_{k} \cdot \mathbf{x}_{t-k}+\boldsymbol{\varepsilon}_{t}(\text { Equation } 1)
$$

The Bayesian information criterion was used for order selection in this study; $\boldsymbol{\Sigma}$ is the residual $\left(\boldsymbol{\varepsilon}_{t}\right)$ covariance matrix with white assumption. For the stationary assumption, $\boldsymbol{\Sigma}$ does not depend on time $t$. For valid Granger causality analysis, MVAR coefficients in Equation 1 must be summable and stable. In this study, the OLS algorithm was used for parameter estimation. The whiteness, consistency, and stationarity of fitted models were confirmed (Barnett \& Seth, 2014; Ding, Bressler, Yang, \& Liang, 2000). The Granger causality matrix $\mathbf{F}$ was determined by the log-likelihood ratio of reduced and full regression. Each element, $f_{j i}$, in $\mathbf{F}$ directionally represented the strength of variable $x_{i}$ to variable $x_{j}$, where $i \neq j$. A two-sample $t$ test was used to examine estimated differences in the brain networks of the engineering and liberal arts students. The workflow of the brain connectivity analysis is shown in Figure 4.

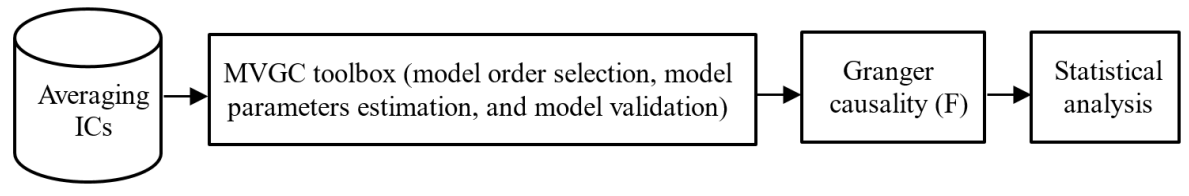

Figure 4. Work-flow of brain connectivity analysis 


\section{Results and Discussion}

The following three sections discuss verbal, numerical, and spatial intelligence. In each section, we first present and describe our results from Granger causality analysis; that is, the estimated brain connectivity in both the problem-identifying and resolution-reaching phases; and subsequently discuss their academic and practical implications.

Verbal intelligence. In this study, a two-sample $t$ test with $\alpha=0.05$ was applied to examine the mean difference in estimated Granger causality $f$ values between the engineering and liberal arts students. Higher $f$ values indicated stronger effects. The findings of the brain connectivity analysis revealed that $\mathrm{K} 4$ played a key role in the problem-identifying phase during verbal intelligence tasks. The mean $f$ values of the links $\mathrm{K} 4$ to $\mathrm{K} 3, \mathrm{~K} 3$ to $\mathrm{K} 4$, and $\mathrm{K} 4$ to $\mathrm{K} 7$ were significantly higher for the engineering students than for the liberal arts students. The analysis also indicated that the hub was located in $\mathrm{K} 4$ (the frontoparietal region), with bidirectional information transfer to K3 (the left temporal region) and unidirectional information transfer to K7 (the right parieto-occipital region). In addition, the mean $f$ value of the link with unidirectional information transfer from K5 (the right temporal region) to K4 was significantly higher for the liberal arts students than for the engineering students. The results of the two-sample $t$ test are listed in Table 1. However, no significant differences in brain connectivity were observed between the engineering and liberal arts students in the resolution-reaching phase. 


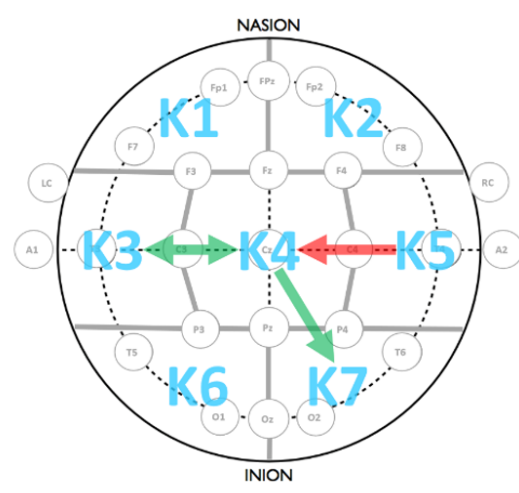

5a. Graphical view

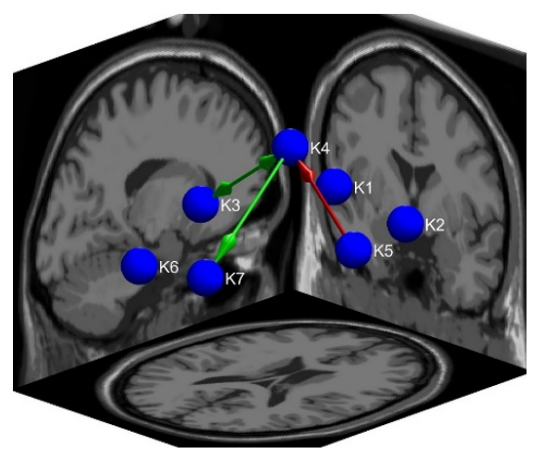

5b. Anatomical view

Figure 5. Estimated brain connectivity in the problem-identifying phase for verbal intelligence tasks.

Note: Arrows represent causality directions (green arrow: engineering $>$ liberal arts; red arrow: liberal arts $>$ engineering).

Table 1

Two-sample t test during PI in the VI task.

\begin{tabular}{|l|l|l|l|l|l|l|l|}
\hline & $\mathrm{K} 1$ & $\mathrm{~K} 2$ & $\mathrm{~K} 3$ & $\mathrm{~K} 4$ & $\mathrm{~K} 5$ & $\mathrm{~K} 6$ & $\mathrm{~K} 7$ \\
\hline $\mathrm{K} 1$ & $\mathrm{NaN}$ & 0.7393 & -0.5646 & 0.2326 & -0.9916 & 0.2398 & 0.8537 \\
\hline $\mathrm{K} 2$ & 0.3481 & $\mathrm{NaN}$ & -0.1144 & -1.039 & -1.1664 & -1.1799 & -0.6748 \\
\hline $\mathrm{K} 3$ & -0.3301 & 0.9148 & $\mathrm{NaN}$ & $\mathbf{2 . 8 7 1 9 * *}$ & -0.5921 & 1.3983 & 0.4331 \\
\hline $\mathrm{K} 4$ & 1.5698 & 1.1403 & $\mathbf{2 . 5 4 6 7 *}$ & $\mathrm{NaN}$ & $\mathbf{- 2 . 2 6 1 1 *}$ & -1.1825 & 1.3321 \\
\hline $\mathrm{K} 5$ & -1.0079 & 0.9141 & -0.0767 & -0.6772 & $\mathrm{NaN}$ & -1.4027 & -0.989 \\
\hline $\mathrm{K} 6$ & -0.5792 & 1.3377 & -1.0649 & -1.8395 & -1.3714 & $\mathrm{NaN}$ & -1.0216 \\
\hline $\mathrm{K} 7$ & 0.8445 & 1.4084 & -0.4992 & $\mathbf{2 . 2 6 8 2 *}$ & -0.7534 & 0.9183 & $\mathrm{NaN}$ \\
\hline
\end{tabular}

Notes: ${ }^{*} \mathrm{p}<0.05 * * \mathrm{p}<0.01 * * * \mathrm{p}<.0 .001$.

PI refers to the problem-identifying phase; VI refers to the verbal intelligence task.

Regarding brain activation during verbal intelligence tasks, Banich and Compton (2018) indicated that the right hemisphere recognises the forms of verbal messages before the left hemisphere constructs abstract representations 


\section{Liu \& Liang - Different Problem-Solving Processes}

of these messages for comprehension. Generally, all the participants in this study followed this pattern in which the right temporal region plays a critical role in recognising words, the frontoparietal region helps to detect mnemonic conflicts, and the left temporal region decodes words. We found that the frontoparietal region (K4), the core of the anterior cingulate cortex (ACC), served as a hub for rapidly transferring information in the problem-identifying phase. The ACC typically controls mechanisms that monitor differential familiarity (Bunge, Burrows, \& Wagner, 2004). Verbal intelligence often involves understanding relationships in statements and drawing conclusions from them or completing an argument; these tasks explain the ACC's role as the hub.

Our EEG analysis continually revealed that compared with the liberal arts students, the engineering students demonstrated more activity in the circulated process between verbal recognition and message comprehension in the problem-identifying phase. By contrast, compared with the engineering students, the liberal arts students spent more cognitive resources in recognising (which might include appreciating) verbal forms and detecting familiarity in that phase. These results suggest that frequently practicing text feature identification and verbal message comprehension can enhance the verbal problem-solving ability of engineering students, whereas continually evoking relevant word families can improve this same type of ability among liberal arts students.

Numerical intelligence. In the problem-identifying phase of numerical intelligence tasks (Figure 6), EEG data revealed that the mean $f$ value of the link with unidirectional information transfer from K5 (the right temporal region) to $\mathrm{K} 3$ (the left temporal region) was significantly higher among the engineering students than among the liberal arts students. In addition, the mean $f$ value of the link with unidirectional information transfer from K6 (the left parieto-occipital region) to K2 (the right frontal region) was significantly higher among the liberal arts students than among the engineering participants. The results of the two-sample $t$ test are listed in Table 2. 


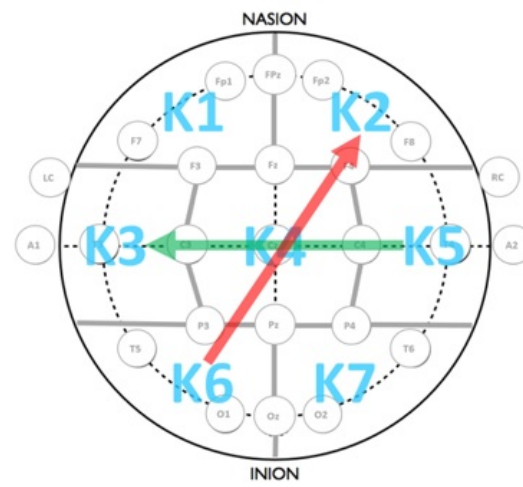

6a. Graphical view

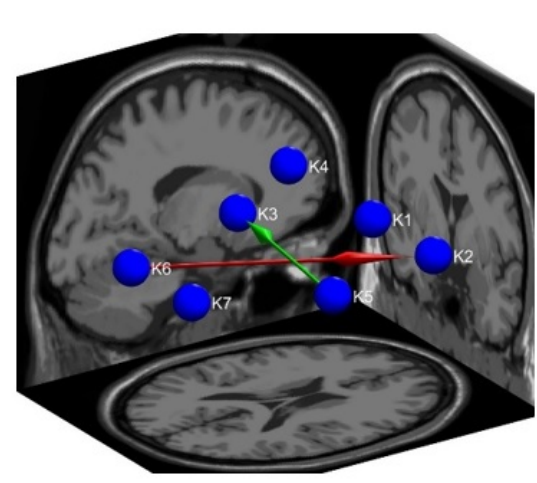

6b. Anatomical view

Figure 6. Estimated brain connectivity in the problem-identifying phase for numerical intelligence tasks.

Note: Arrows represent causality directions (green arrow: engineering $>$ liberal arts; red arrow: liberal arts $>$ engineering).

Table 2

Two-sample t test during PI in the NI task.

\begin{tabular}{|l|l|l|l|l|l|l|l|}
\hline & $\mathrm{K} 1$ & $\mathrm{~K} 2$ & $\mathrm{~K} 3$ & $\mathrm{~K} 4$ & $\mathrm{~K} 5$ & $\mathrm{~K} 6$ & $\mathrm{~K} 7$ \\
\hline $\mathrm{K} 1$ & $\mathrm{NaN}$ & 0.8613 & -1.1419 & -0.0525 & -0.78 & -1.0423 & -0.0787 \\
\hline $\mathrm{K} 2$ & -0.7671 & $\mathrm{NaN}$ & 0.1246 & 0.102 & -1.3734 & $\mathbf{- 2 . 9 3 9 8 *}$ & -1.8396 \\
\hline $\mathrm{K} 3$ & 0.3222 & 1.1892 & $\mathrm{NaN}$ & -0.3952 & $\mathbf{2 . 2 0 5 5 *}$ & 1.1689 & 0.2103 \\
\hline $\mathrm{K} 4$ & 1.2449 & 0.743 & -1.2299 & $\mathrm{NaN}$ & -0.1271 & -1.8574 & 0.7677 \\
\hline K5 & -1.0309 & -1.2693 & 0.4234 & 1.4348 & $\mathrm{NaN}$ & 1.0058 & -1.2959 \\
\hline K6 & 0.9496 & -1.1074 & 0.2424 & 0.9608 & -0.5243 & $\mathrm{NaN}$ & 1.3423 \\
\hline K7 & 0.0365 & -1.4683 & -0.2 & -0.6376 & 1.1758 & 1.2864 & $\mathrm{NaN}$ \\
\hline
\end{tabular}

Notes: $* \mathrm{p}<0.05 * * \mathrm{p}<0.01 * * * \mathrm{p}<.0 .001$.

PI refers to the problem-identifying phase; NI refers to the numerical intelligence task.

Regarding brain activation during numerical intelligence tasks, recent studies have suggested that the extent of numerical processing depends on the 


\section{Liu \& Liang - Different Problem-Solving Processes}

frontal and parietal regions of both hemispheres (Ansari, 2007; Cohen Kadoshsend et al., 2010; Kanjliaa et al., 2016). Generally, the frontoparietal network (including the prefrontal cortex) of all the participants in this study was activated during numerical intelligence tasks. We found that the ACC in the frontoparietal region (K4) still acts as a core for promptly transferring information in the problem-identifying phase. Numerical intelligence often involves figures and thinking, quantity discrimination, and identification of odd alphanumeric characters, highlighting the functions of cost calculation and error monitoring, which are controlled by the ACC (Apps, Rushworth, \& Chang, 2016; Bunge et al., 2004).

EGG analysis revealed that compared with the liberal arts students, the engineering students used more cognitive resources for transferring information from number recognition and nonverbal communication (the right temporal region) (Banich \& Compton, 2018; Wisniewski, Wendling, Manning, \& Steinhoff, 2012) to verbal comprehension and calculation ability (the left temporal region) (Banich \& Compton, 2018; Takeuchi et al., 2011) in the problem-identifying phase. By contrast, the liberal arts students used more cognitive resources for transferring information from verbal perception (the left parieto-occipital region) (Boccia, Piccardi, Palermo, Nori, \& Palmiero, 2015) to emotion regulation and thought (the right frontal region) (Dennis \& Solomon, 2010; Gallup \& Platek, 2002) in the same phase. These results indicate that the engineering students in this study devoted their efforts to calculation directly, whereas the liberal arts students exhibited more activity with question reading and understanding. Practicing mathematical skills and improving them through daily life tasks and personal reflections have proven effective in developing students' confidence and awareness of their numerical competence (Attridge \& Inglis, 2013; Shelton, 2016).

In the resolution-reaching phase (Figure 7 ), the mean $f$ value of the link with unidirectional information transfer from $\mathrm{K} 3$ (the left temporal region) to K6 (the left parieto-occipital region) was significantly higher among the engineering students than among the liberal arts students. Moreover, the mean f value of the link with unidirectional information transfer from K5 (the right temporal region) to K1 (the left frontal region) was significantly higher among 
the engineering students than among the liberal arts students. The results of the two-sample $t$ test are listed in Table 3 .

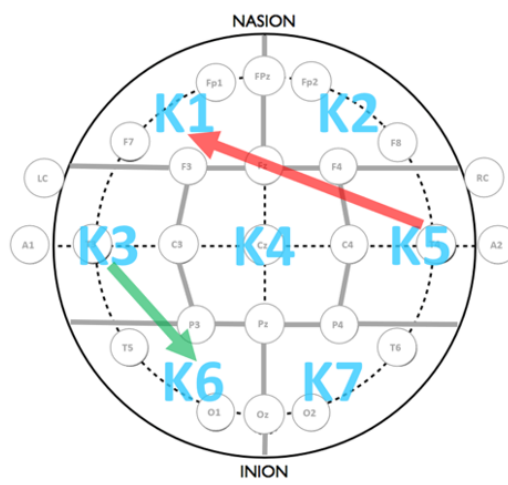

7a. Graphical view

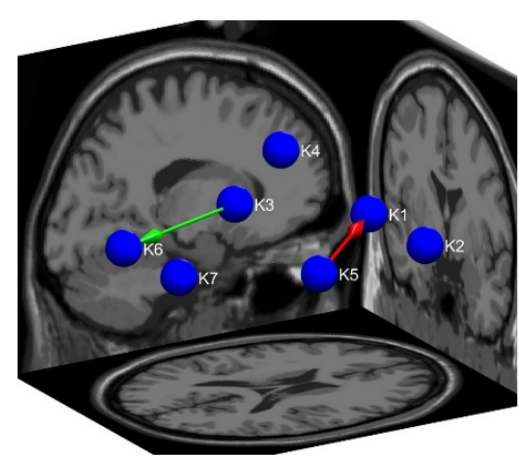

7b. Anatomical view

Figure 7. Estimated brain connectivity in the resolution-reaching phase for numerical intelligence tasks.

Note: Arrows represent causality directions (green arrow: engineering $>$ liberal arts; red arrow: liberal arts $>$ engineering).

Table 3

Two-sample t test during RR in the NI task.

\begin{tabular}{|l|l|l|l|l|l|l|l|}
\hline & $\mathrm{K} 1$ & $\mathrm{~K} 2$ & $\mathrm{~K} 3$ & $\mathrm{~K} 4$ & $\mathrm{~K} 5$ & $\mathrm{~K} 6$ & $\mathrm{~K} 7$ \\
\hline $\mathrm{K} 1$ & $\mathrm{NaN}$ & 1.4316 & 1.5772 & -0.9515 & $\mathbf{- 3 . 1 0 6 5} * *$ & -1.0458 & 1.298 \\
\hline $\mathrm{K} 2$ & 0.7258 & $\mathrm{NaN}$ & 1.4791 & -0.687 & 0.3406 & -0.1347 & -0.4229 \\
\hline $\mathrm{K} 3$ & -0.3053 & 1.9333 & $\mathrm{NaN}$ & 1.3013 & 0.7441 & 0.7465 & 1.1244 \\
\hline K4 & -1.4704 & -0.8596 & -1.1851 & $\mathrm{NaN}$ & -0.0273 & 1.1527 & -1.5855 \\
\hline K5 & -0.7932 & 0.5625 & -0.3509 & 1.1693 & $\mathrm{NaN}$ & 0.8198 & -1.7789 \\
\hline K6 & -0.7253 & 0.9124 & $\mathbf{2 . 9 0 4 5 * *}$ & 0.6578 & 0.8425 & $\mathrm{NaN}$ & -0.2845 \\
\hline K7 & 1.2404 & -0.585 & 0.4952 & 0.8784 & -1.315 & 1.0403 & $\mathrm{NaN}$ \\
\hline
\end{tabular}

Notes: $* \mathrm{p}<0.05 * * \mathrm{p}<0.01 * * * \mathrm{p}<.0 .001$.

$\mathrm{RR}$ refers to the resolution-reaching phase; NI refers to the numerical intelligence task. 
Compared with their counterparts, the engineering students used more cognitive resources for transferring information from verbal comprehension and calculation ability (the left temporal region) to verbal perception (the left parieto-occipital region) in the resolution-reaching phase. By contrast, the liberal arts students used more cognitive resources for transferring information from number recognition and nonverbal communication (the right temporal region) to mathematical cognition and analogical reasoning (the left frontal region) (Aichelburg et al., 2016; Arsalidou \& Taylor, 2011) in the same phase. These results suggest that the engineering students shifted their focus to answer selection, whereas the liberal arts students still focused on logical thinking in this phase.

Spatial intelligence. In the problem-identifying phase of spatial intelligence tasks (Figure 8), the mean $f$ value of the link with unidirectional information transfer from K2 (the right frontal region) to K6 (the left parietooccipital region) was significantly higher among the engineering students than among the liberal arts students. In addition, the mean $f$ value of the link with unidirectional information transfer from $\mathrm{K} 3$ (the left temporal region) to $\mathrm{K} 1$ (the left frontal region) was significantly higher among the liberal arts students than among the engineering students. The results of the two-sample $t$ test are listed in Table 4. 


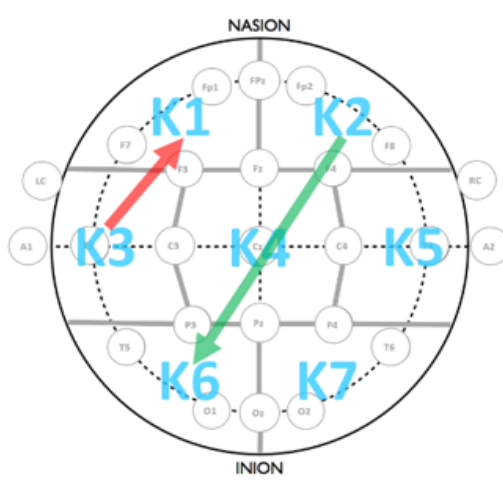

8a. Graphical view

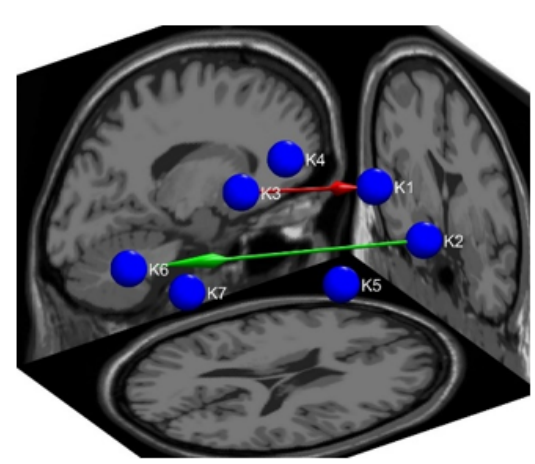

8 b. Anatomical view

Figure 8. Estimated brain connectivity in the problem-identifying phase for spatial intelligence tasks.

Note: Arrows represent causality directions (green arrow: engineering > liberal arts; red arrow: liberal arts $>$ engineering).

Table 4

Two-sample t test during PI in the SI task.

\begin{tabular}{|l|l|l|l|l|l|l|l|}
\hline & K1 & K2 & K3 & K4 & K5 & K6 & K7 \\
\hline K1 & NaN & 0.181 & $-\mathbf{2 . 4 4 3 4 *}$ & 2.0338 & 0.0689 & 0.4458 & 0.3108 \\
\hline K2 & -0.9914 & NaN & -1.4304 & 1.0794 & 0.7705 & -0.4572 & -0.9455 \\
\hline K3 & -0.7294 & -0.2413 & NaN & -1.4627 & 0.4938 & 1.1515 & 1.2212 \\
\hline K4 & 0.8548 & 0.0122 & -1.7075 & NaN & -0.0071 & 0.1523 & -0.2069 \\
\hline K5 & 0.4456 & 1.6171 & -0.1733 & 0.1819 & NaN & 0.1688 & 0.6987 \\
\hline K6 & 0.034 & $\mathbf{2 . 2 7 3 9 *}$ & 0.9924 & 0.3756 & 1.1798 & NaN & 0.2915 \\
\hline K7 & 0.4022 & -1.5419 & 1.1718 & 1.8707 & -0.5287 & 2.0504 & NaN \\
\hline
\end{tabular}

Notes: $* \mathrm{p}<0.05 * * \mathrm{p}<0.01 * * * \mathrm{p}<.0 .001$.

PI refers to the problem-identifying phase; SI refers to the spatial intelligence task.

Regarding brain activation during spatial intelligence tasks, Burgess (2008) indicated that to construct spatial cognitions, the hippocampus and medial temporal lobe provide allocentric environmental representations, the 


\section{Liu \& Liang - Different Problem-Solving Processes}

parietal lobe provides egocentric representations, and the retrosplenial cortex and parieto-occipital sulcus enable the representations to interact. Generally, the spatial processing network of all participants in this study was activated during the experiment.

Compared with their their counterparts, the engineering students used more cognitive resources transferring information from spatial relation integration and emotional thought (the right frontal region) to verbal perception (the left parieto-occipital region) in the problem-identifying phase. By contrast, the liberal arts students used more cognitive resources for transferring information from verbal comprehension (questions) (the left temporal region) to analogical reasoning (the left frontal region) in the same phase. These results indicate that the engineering students in this study resolved verbal-form questions based on spatial relation integration (Han, Cao, Cao, Gao, \& Li, 2016), whereas the liberal arts students attempted to retrieve spatial context memory by comprehending questions in verbal form (Slotnick, Moo, Segal, \& Hart, 2003). Increasing evidence suggests that playing with spatially oriented toys (e.g. puzzles and blocks) correlates with spatial development (e.g. Jirout \& Newcombe, 2015), and innovative technologies, such as virtual and augmented reality, add promising possibilities to improve spatial problem-solving ability (Dominguez, MartinGutierrez, Gonzalez, \& Corredeaguas, 2012).

Analysis of the resolution-reaching phase (Figure 9) revealed critical roles of $\mathrm{K} 5$ and $\mathrm{K} 7$. The mean $f$ values of the links $\mathrm{K} 5$ to $\mathrm{K} 7, \mathrm{~K} 5$ to $\mathrm{K} 2$, and $\mathrm{K} 3$ to K7 were significantly higher among the engineering students than among the liberal arts students. We found that the hub was located in K5 (the right temporal region) with unidirectional information transfer to $\mathrm{K} 2$ (the right frontal region) and $\mathrm{K} 7$ (the right parieto-occipital region). In addition, $\mathrm{K} 7$ was observed to play a critical role with unidirectional information transfer from $\mathrm{K} 3$ (the left temporal region) and K5. Furthermore, the mean $f$ value of the link with unidirectional information transfer from K1 (the left frontal region) to K2 was significantly higher among the liberal arts students than among the engineering students. The results of the two-sample $t$ test are listed in Table 5 . 


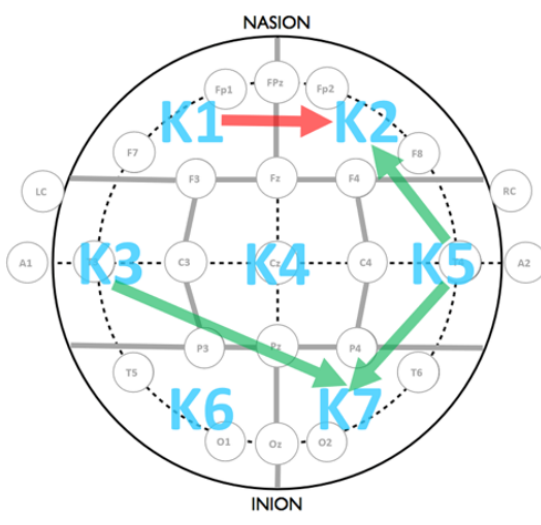

9a. Graphical view

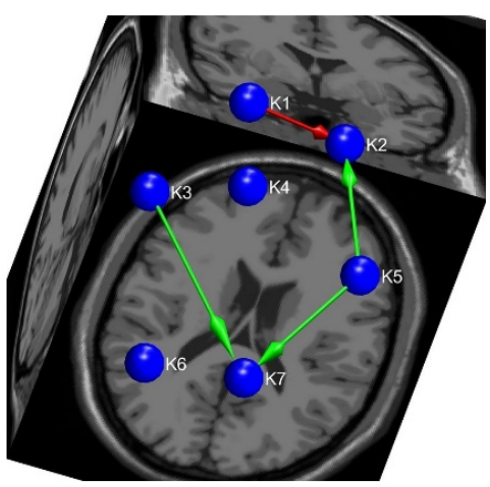

9b. Anatomical view

Figure 9. Estimated brain connectivity in the resolution-reaching phase for spatial intelligence tasks.

Note: Arrows represent causality directions (green arrow: engineering > liberal arts; red arrow: liberal arts $>$ engineering).

\section{Table 5}

Two-sample $\mathrm{t}$ test during $R R$ in the SI task.

\begin{tabular}{|l|l|l|l|l|l|l|l|}
\hline & K1 & K2 & K3 & K4 & K5 & K6 & K7 \\
\hline K1 & NaN & 0.181 & $-\mathbf{2 . 4 4 3 4 *}$ & 2.0338 & 0.0689 & 0.4458 & 0.3108 \\
\hline K2 & -0.9914 & NaN & -1.4304 & 1.0794 & 0.7705 & -0.4572 & -0.9455 \\
\hline K3 & -0.7294 & -0.2413 & NaN & -1.4627 & 0.4938 & 1.1515 & 1.2212 \\
\hline K4 & 0.8548 & 0.0122 & -1.7075 & NaN & -0.0071 & 0.1523 & -0.2069 \\
\hline K5 & 0.4456 & 1.6171 & -0.1733 & 0.1819 & NaN & 0.1688 & 0.6987 \\
\hline K6 & 0.034 & $\mathbf{2 . 2 7 3 9 *}$ & 0.9924 & 0.3756 & 1.1798 & NaN & 0.2915 \\
\hline K7 & 0.4022 & -1.5419 & 1.1718 & 1.8707 & -0.5287 & 2.0504 & NaN \\
\hline
\end{tabular}

Notes: $* p<0.05 * * p<0.01 * * * p<.0 .001$.

$\mathrm{RR}$ refers to the resolution-reaching phase; SI refers to the spatial intelligence task.

Compared with their counterpartsCompared with their counterparts, the engineering students used more cognitive resources for transferring information from nonverbal communication (the right temporal region) to spatial relation integration and emotional thought (the right frontal region) and 


\section{Liu \& Liang - Different Problem-Solving Processes}

spatial attention (the right parieto-occipital region) as well as from verbal comprehension (the left temporal region) to spatial attention and visual perception (the right parieto-occipital region) (Corbetta \& Shulman, 2002; Malhotra, Coulthard, \& Husain, 2009) in the resolution-reaching phase. By contrast, the liberal arts students used more cognitive resources for transferring information from spatial thinking and analogical reasoning (the left frontal region) to spatial relation integration and emotional thought (the right frontal region) in the same phase. These results suggest that the engineering students activated their spatial processing network to recognise spatial configurations, maintain spatial awareness, and integrate spatial relationships (Malhotra, Coulthard, \& Husain, 2009; Sakurai, Hamada, Tsugawa, \& Sugimoto, 2015), whereas the liberal arts students built spatial relationships through contextual information and reasoning in this phase.

Research limitations. The use of EEG generated several research limitations. First, problem-solving is a complex process; however, neuroscience studies have typically inspected small-scale and simple cognitive processes. Complicated connections and patterns of brain activity render logical conclusions difficult. Second, the small number of participants limits the generalisability of the current findings. Thus, whether the results and conclusions would be the same for a general population, including different levels of academic performance and diverse disciplines, remains unclear. Third, the three types of intelligence test questions used in this study limit the experimental findings. Additional types of IQ test questions and supplementary items can help increase validity.

\section{Conclusions and Reflections}

Despite the aforementioned limitations, three broad conclusions can be drawn. (i) Regarding brain activation during verbal intelligence tasks, major differences between the engineering and liberal arts students were observed in the information flows of verbal message comprehension and contextual familiarity detection in the problem-identifying phase. However, no significant difference was observed between the two groups in the resolutionreaching phase. (ii) Regarding brain activation during numerical intelligence 
tasks, major differences between the two groups were observed in the information flows of mental calculations and message comprehension in the problem-identifying phase and those of verbal perception and analogical reasoning in the resolution-reaching phase. (iii) Regarding brain activation during spatial intelligence tasks, major differences between the two groups were observed in the information flows of spatial relation integration and spatial context memory retrieval in the problem-identifying phase and those of spatial attention and contextual relation integration in the resolutionreaching phase.

The aforementioned research findings indicate the differences in problemsolving processes between engineering and liberal arts students. Broadly speaking, the engineering students in the experiment tended to focus on certain tasks, whereas the liberal arts students favoured the contextual aspects of a task. Each can benefit from the other in terms of professional cultivation; that is, engineers should think about how invented technologies can be used in diverse sociocultural contexts and refine them accordingly, whereas liberal arts professionals should learn how engineers realise unusual ideas. Few studies have examined differences in problem-solving processes between students of distinct disciplines, but the importance of integrative intelligence to neuroscience research should be highlighted. This original provides potential for future inquiries on this research theme.

\section{References}

Aichelburg, C., Urbanski, M., de Schotten, M. T., Humbert, F., Levy, R., \& Volle, E. (2016). Morphometry of left frontal and temporal poles predicts analogical reasoning abilities. Cerebral Cortex, 26, 915-932. doi:

$10.1093 /$ cercor/bhu254

Ansari, D. (2007). Does the parietal cortex distinguish between "10", "ten," and ten dots? Neuron, 53(2), 165-167. doi: 10.1016/j.neuron.2007.01.001 Apps, M. A. J., Rushworth, M. F. S., \& Chang, S. W. C. (2016). The anterior cingulate gyrus and social cognition: Tracking the motivation of others. Neuron, 90(4), 692-707. doi: 10.1016/j.neuron.2016.04.018 Arsalidou, M., \& Taylor, M. J. (2011). Is $2+2=4$ ? Meta-analyses of brain areas needed for numbers and calculations. Neuroimage, 54(3), 23822393. doi: 10.1016/j.neuroimage.2010.10.009 


\section{Liu \& Liang - Different Problem-Solving Processes}

Attridge, N., \& Inglis, M. (2013). Advanced mathematical study and the development of conditional reasoning skills. PLoS One, 8(7): e69399. doi: 10.1371/journal.pone.0069399

Banich, M. T., \& Compton, R. J. (2018). Cognitive neuroscience $\left(4^{\text {th }} \mathrm{ed}\right.$.).

Cambridge, UK: Cambridge University Press.

Barbey, A. K., Colom, R., Solomon, J., Krueger, F., Forbes, C., \& Grafman, J. (2012). An integrative architecture for general intelligence and executive function revealed by lesion mapping. Brain: A Journal of Neurology, 135, 1154-1164. doi: 10.1093/brain/aws021

Barbey, A. K., \& Sloman, S.A. (2007). Base-rate respect: From ecological rationality to dual processes. Behavioral and Brain Sciences, 30, 241254. doi: 10.1017/S0140525X07001653

Barnett, L., \& Seth, A. K. (2014). The MVGC multivariate Granger causality toolbox: A new approach to Granger-causal inference. Journal of Neuroscience Methods, 223, 50-68, 2014. doi:

10.1016/j.jneumeth.2013.10.018

Basagni, B., Luzzatti, C., Navarrete, E., Caputo, M., Scrocco, G.,

Damora, A., Giunchi, L., Gemignani, P., Caiazzo, A., Gambini, M. G., Avesani, R., Mancuso, M., Trojano, L., \& De Tanti, A. (2017). VRT (verbal reasoning test): A new test for assessment of verbal reasoning. Test realisation and Italian normative data from a multicentric study. Neurological Science, 38(4), 643-650. doi: 10.1007/s10072-017-2817-9

Bastos, A. M., \& Schoffelen, J.-M. (2016). A tutorial review of functional connectivity analysis methods and their interpretation pitfalls. Frontiers in System Neuroscience, 9(Pt 2), article 175. doi:

10.3389/fnsys.2015.00175

Bishop, S. J., Fossella, J., Croucher, C. J., \& Duncan, J. (2008). COMT val158met genotype affects neural mechanisms supporting fluid intelligence. Cerebral Cortex, 18(9), 2132-2140. doi:

10.1093/cercor/bhm240

Boccia, M., Piccardi, L., Palermo, L., Nori, R., \& Palmiero, M. (2015). Where do bright ideas occur in our brain? Meta-analytic evidence from neuroimaging studies of domain-specific creativity. Frontiers in Psychology, 6, Article 1195. doi: 10.3389/fpsyg.2015.01195

Bordoloi, L. M., \& Winebrake, J. J. (2015). Bringing the liberal arts to engineering education. The Chronicle of Higher Education, April 27. Retrieved from https://www.chronicle.com/article/Bringing-the-LiberalArts-to/229671 
Bressler, S. L., \& Seth, A. K. (2011). Wiener-Granger Causality: A well established methodology. NeuoImage, 58(2), 323-329. doi:

10.1016/j.neuroimage.2010.02.059

Bunge, S. A., Burrows, B., \& Wagner, A. D. (2004). Prefrontal and hippocampal contributions to visual associative recognition: Interactions between cognitive control and episodic retrieval. Brain and Cognition, 56(2), 141-152. doi: 10.1016/j.bande.2003.08.001

Burgess, N. (2008). Spatial cognition and the brain. Annals of the New York Academy of Sciences, 1124, 77-97. doi: 10.1196/annals. 1440.002

Carter, P. J., \& Russell, K. A. (2008). Test and assess your IQ: Numeric, verbal, and spatial aptitude tests. London, UK: Kogan Page.

Cohen Kadoshsend, R., Soskic, S., Iuculano, T., Kanai, R., \& Walsh, V. (2010). Modulating neuronal activity produces specific and long-lasting changes in numeric competence. Current Biology, 20(22), 2016-2020. doi: 10.1016/j.cub.2010.10.007

Corbetta, M., \& Shulman, G. L. (2002). Control of goal-directed and stimulus driven attention in the brain. Nature Reviews Neuroscience, 3(3), 201-215. doi: 10.1038/nrn755

Deary, I. J., Penke, L., \& Johnson, W. (2010). The neuroscience of human intelligence differences. Nature Reviews Neuroscience, 11, 201-211. doi: $10.1038 / \mathrm{nrn} 2793$

Delorme, A., \& Makeig, S. (2004). EEGLAB: an open source toolbox for analysis of single-trial EEG dynamics including independent component analysis. Journal of Neuroscience Methods, 134, 9-21.

Delorme, A., Palmer, J., Onton, J., Oostenveld, R., \& Makeig, S. (2012). Independent EEG sources are dipolar. PLoS ONE, 7(2), e30135. doi: 10.1016/j.jneumeth.2003.10.009

Dennis, T. A., \& Solomon, B. (2010). Frontal EEG and emotion regulation: Electrocortical activity in response to emotional film clips is associated with reduced mood Induction and attention interference effects. Biological Psychology, 85(3), 456-464. doi:

10.1016/j.biopsycho.2010.09.008

Ding, M., Bressler, S. L., Yang, W., \& Liang, H. (2000). Short-window spectral analysis of cortical event-related potentials by adaptive multivariate autoregressive modeling: Data preprocessing, model validation, and variability assessment. Biological Cybernetics, 83(1), 3545. doi: 10.1007/s004229900137 
Dominguez, M. G., Martin-Gutierrez, J., Gonzalez, C. R., \& Corredeaguas, C. M. M. (2012). Methodologies and tools to improve spatial ability. Procedia: Social and Behavioral Sciences, 51, 736-744. doi:

10.1016/j.sbspro.2012.08.233

Duncan, J., Seitz, R. J., Kolodny, J., Bor, D., Herzog, H., Ahmed, A., Newell, F. N., \& Emslie, H. (2000). A neural basis for general intelligence. Science, 289(5478), 457-460. doi:

10.1126/science.289.5478.457

Friston, K. J., Bastos, A. M., Oswal, A., van Wijk, B., Richter, C., \& Litvak, V. (2014). Granger causality revisited. NeuroImage, 101, 796-808. doi: 10.1016/j.neuroimage.2014.06.062

Gallup, G. G. J., \& Platek, S. M. (2002). Cognitive empathy presupposes self-awareness: Evidence from phylogeny, ontogeny, neuropsychology and mental illness. Behavioral and Brain Sciences, 25(1), 36-37. doi: 10.1017/S0140525X02380014

Gläscher, J., Rudrauf, D., Colom, R., Paul, L. K., Tranel, D., Damasio, H., \& Adolphs, R. (2010). Distributed neural system for general intelligence revealed by lesion mapping. Proceedings of the National Academy of Sciences (PNAS), 107(10), 4705-4709. doi: 10.1073/pnas.0910397107

Granger, C. W. J. (1969). Investigating causal relations by econometric models and cross-spectral methods. Econometrica, 37, 424-438. doi: $10.2307 / 1912791$

Han, J., Cao, B., Cao, Y., Gao, H., \& Li, F. (2016). The role of right frontal brain regions in integration of spatial relation. Neuropsychologia, 86, 2937. doi: 10.1016/j.neuropsychologia.2016.04.008

Hanson, S. J., \& Bunzl, M. (2010). Foundational issues in human brain mapping. Cambridge, MA: The MIT Press.

Ivanitskii, A. M., Portnova, G. V., Martynova, O. V., Maiorova, L. A., \& Fedina, O. N., \& Petrushevskii, A. G. (2015). Brain mapping in verbal and spatial thinking. Neuroscience and Behavioral Physiology, 45(2), 146-153. doi: 10.1007/s11055-015-0052-5

Jenkins, W. K. (2014). Today's engineering education is a liberal arts education of the future. Proceedings of the IEEE, 102(9), 1306-1309. doi: 10.1109/JPROC.2014.2341311

Jirout, J. J., \& Newcombe, N. S. (2015). Building blocks for developing spatial skills: evidence from a large, representative U.S. sample. Psychological Science, 26(3), 302-310. doi: 10.1177/0956797614563338 
Jung, T.-P., Makeig, S., Mckeown, M. J., Bell, A. J., Lee, T.-W., \& Sejnowski, T. J. (2001). Imaging brain dynamics using independent component analysis. Proceedings of the IEEE, 89(7), 1107-1122. doi: $10.1109 / 5.939827$

Kanjliaa, S., Lanea, C, Feigensona, L., \& Bedny, M. (2016). Absence of visual experience modifies the neural basis of numeric thinking. Proceedings of the National Academy of Sciences (PNAS), 113(40), 11172-11177. doi: 10.1073/pnas.1524982113

Lachman, M. E., Agrigoroaei, S., Murphy, A., \& Tun, P. A. (2010). Frequent cognitive activity compensates for education differences in episodic memory. The American Journal of Geriatric Psychiatry, 18(1), 4-10. doi: 10.1097/JGP.0b013e3181ab8b62

Liang, C., Lin, C.-T., Yao, S.-N., Chang, W.-S., Liu, Y.-C., \& Chen, S.-A. (2017). Visual attention and association: An electroencephalography study in expert designers. Design Studies, 48, 76-95. doi: 10.1016/j.destud.2016.11.002

Lin, C.-T., Chuang, C.-H., Kerick, S., Mullen, T., Jung, T.-P., Ko, L.-W., Chen, S.-A., King, J.-T., \& McDowell, K. (2016). Mind-wandering tends to occur under low perceptual demands during driving. Scientific Reports, 6, article 20353. doi: 10.1038/srep21353

Liu, Y.-C., Chang, C.-C., Yang, Y.-H., \& Liang, C. (2018). Spontaneous analogising caused by text stimuli in design thinking: Differences between higher- and lower-creativity groups. Cognitive Neurodynamics. doi: 10.1007/s11571-017-9454-0

Malhotra, P., Coulthard, E. J., \& Husain, M. (2009). Role of right posterior parietal cortex in maintaining attention to spatial locations over time. Brain, 132(3), 645-660. doi: 10.1093/brain/awn350

Miller, E. K., \& Cohen, J. D. (2001). An integrative theory of prefrontal cortex function. Annual Review of Neuroscience, 24, 167-202. doi: 10.1146/annurev.neuro.24.1.167

Miller, E. K., \& Phelps, E. A. (2010). Current opinion in neurobiology: Cognitive neuroscience 2010. Current Opinion in Neurobiology, 20(2), 141-142. doi: 10.1016/j.conb.2010.03.008

Neumann, Y. (1983). Differences between engineering and liberal arts: A discriminant analysis of students' work values. Journal of Experimental Education, 52(1), 41-46. doi: 10.1080/00220973.1983.11011871

Oakhill, J., Yuill, N., \& Garnham, A. (2011). The differential relations between verbal, numerical and spatial working memory abilities and 
children's reading comprehension. International Electronic Journal of Elementary Education, 4(1), 83-106. Retrieved from https://files.eric.ed.gov/fulltext/EJ1068618.pdf

Paul, E. J., Larsen, R. J., Nikolaidis, A., Ward, N., Hillman, C. H., Cohen, N. J., Kramer, A. F., \& Barbey, A. K. (2016). Dissociable brain biomarkers of fluid intelligence. NeuroImage, 137, 201-211. doi: 10.1016/j.neuroimage.2016.05.037

Ritchie, S. J., Bates, T. C., \& Deary, I. J. (2015). Is education associated with improvements in general cognitive ability, or in specific skills? Developmental Psychology, 51(5), 573-582. doi: 10.1037/a0038981

Sakurai, Y., Hamada, K., Tsugawa, N., \& Sugimoto, I. (2015). Ventral simultanagnosia and prosopagnosia for unfamiliar faces due to a right posterior superior temporal sulcus and angular gyrus lesion. Neurocase, 22(1), 122-129. doi: 10.1080/13554794.2015.1066827

Shelton, C. (2016). Students who developed logical reasoning skills reported improved confidence in drug dose calculation: Feedback from remedial maths classes. Nurse Education Today, 41, 6-11. doi:

10.1016/j.nedt.2016.03.007

Slotnick, S. D., Moo, L. R., Segal, J. B., \& Hart, J. Jr. (2003). Distinct prefrontal cortex activity associated with item memory and source memory for visual shapes. Cognitive Brain Research, 17(1), 75-82. doi: 10.1016/s0926-6410(03)00082-x

Spearman, C. (1904). General intelligence: Objectively determined and measured. American Journal of Psychology, 15(2), 201-293. doi: $10.2307 / 1412107$

Takeuchi, H., Taki, Y., Sassa, Y., Hashizume, H., Sekiguchi, A., Fukushima, A., \& Kawashima, R. (2011). Working memory training using mental calculation impacts regional gray matter of the frontal and parietal regions. PLoS One, 6(8), e23175. doi: 10.1371/journal.pone.0023175 Wang, H. E., Bénar, C. G., Quilichini, P. P., Friston, K. J., Jirsa, V. K., \& Bernard, C. (2014). A systematic framework for functional connectivity measures. Frontiers in Neuroscience, 8 , article 405. doi:

10.3389/fnins.2014.00405

Wisniewski, I., Wendling, A. S., Manning, L., \& Steinhoff, B. J. (2012). Visuo-spatial memory tests in right temporal lobe epilepsy foci: Clinical validity. Epilepsy \& Behavior, 23(3), 254-260. doi:

10.1016/j.yebeh.2011.12.006 
Yao, S.-N., Lin, C.-T., King, J.-T., Liu, Y.-C., \& Liang, C. (2017). Learning in the visual association of novice and expert designers. Cognitive Systems Research, 43, 76-88. doi: 10.1016/j.cogsys.2017.01.005

Yu-Cheng Liu, is a Postdoctoral Researcher, Department of BioIndustry Communication and Development, National Taiwan University, Taipei, Taiwan.

Chaoyun Liang, is a Distinguished Professor, Department of BioIndustry Communication and Development, National Taiwan University, Taipei, Taiwan.

Contact Address: Chaoyun Liang, Department of Bio-Industry Communication and Development, National Taiwan University, No. 1, Sec. 4, Roosevelt Road, Taipei, 10617, Taiwan.

Email: cliang@ntu.edu.tw 